\title{
A Correlation between Compaction Characteristics and Soil Index Properties for Fine-grained Soils
}

\author{
Hunar F. H. Ali', Ahmed J. H. Rash², Madeh I. Hamakareem², Daban A. Muhedin² \\ ${ }^{1}$ Department of Civil Engineering, University of Halabja, Halabja, Iraq, ${ }^{2}$ Department of Geotechnical Engineering, Faculty of Engineering, \\ Koya University KOY45, Kurdistan Region - F.R. Iraq
}

\author{
${ }^{*}$ Correspondence author: \\ Hunar F. H. Ali, \\ Department of Civil \\ Engineering, University \\ of Halabja, Halabja, Iraq. \\ E-mail: hunar.hamaali@uoh. \\ edu.iq \\ Received: 01 August 2019 \\ Accepted: 03 September \\ 2019 \\ Published: 01 December 2019 \\ DOI \\ 10.25156/ptj.v9n2y2019.pp93-99
}

\section{A B S TR A C T}

This paper addresses the correlation between the liquid and/or plastic limits with the compaction characteristics, maximum dry density, and optimum moisture content (OMC), for fine-grained soils. In the previous studies, several attempts have been made to identify these two important parameters from other simple soil properties such as index soil properties. Some concluded that liquid limit shows a good correlation with compaction characteristics, while others observed that plastic limit does. In this work, many soil samples have been taken from various locations around Koya city and the required tests have been carried out. The results have been illustrated to identify whether soil index properties can correlate with the compaction characteristics. It is concluded that neither plastic limit nor liquid limit can provide an adequate correlation with maximum dry density and OMC. Contrary to the literature, liquid limit provides better correlations.

Keywords: Liquid limit; Maximum dry density; Optimum water content; Plastic limit

\section{INTRODUCTION}

Soil compaction is an essential process to increase the stability of soil. This can be performed using mechanical force to pack soil particle closer. Soil compaction can increase the density of soil as the voids between the particles decrease. It can, therefore, improve the soil properties. This will result in the increment of shear strength and modification of volume change characteristics. It will also reduce the settlement and hydraulic conductivity of the soil. In field, this process is usually carried out using heavy mechanical machines. In the construction of many earth structures, such as embankment, it is crucial to evaluate the suitability of the soil with regard to compaction characteristics. The compaction characteristics of a soil obtained from laboratory testing are the maximum dry density $\left(\gamma_{d \text { max }}\right)$ and optimum moisture content (OMC). To do this, either Standard Proctor Test or Modified Proctor Test can be used. The laboratory data of compaction characteristics are used to quantify the compaction of natural site materials at a satisfactory level (Budhu, 2015 and Powrie, 2014).

Although the determination of compaction parameters from a laboratory compaction test is simple, it is time consuming as large quantities of soil are required for testing in many projects such as embankments and roads. It might be difficult to obtain the required type of soil in one area and it is desired to be tested so that the suitability of the soil for the required purpose can be assessed. Of course, the delay in testing results can adversely impact project timing and the search for source of suitable material. Hence, it can be advantageous to use the correlation between the compaction parameters and simple soil index properties for the preliminary assessment of the suitability of a soil for a particular project (Pillai and Vinod, 2015).

Several attempts have been made to determine a relationship between compaction characteristics and plasticity of soil (McRae, 1958; Daniel and Benson, 1990; Daniel and Wu, 1993; Benson and Trast, 1995; Blotz et al., 1998; Gurtug and Sridharan, 2004; Sridharan and Nagaraj, 2005). Figure 1 shows the plot between OMC and liquid limit (wL). From this figure, it can be observed that with the increase of wL, OMC increases. However, remarkable scatter of data can be seen, especially at higher values of liquid limit.

Similarly, Figure 2 demonstrates a plot of maximum dry density against the liquid limit, which shows the decrement of $\gamma_{d \max }$ with the increase in the wL, but again with a considerable scatter.

Figure 3 illustrates the relationship between $\mathrm{OMC}$ and plastic limit (wP). It can also be noted that there is an increasing in trend of $\mathrm{OMC}$ with the increment of wP. 


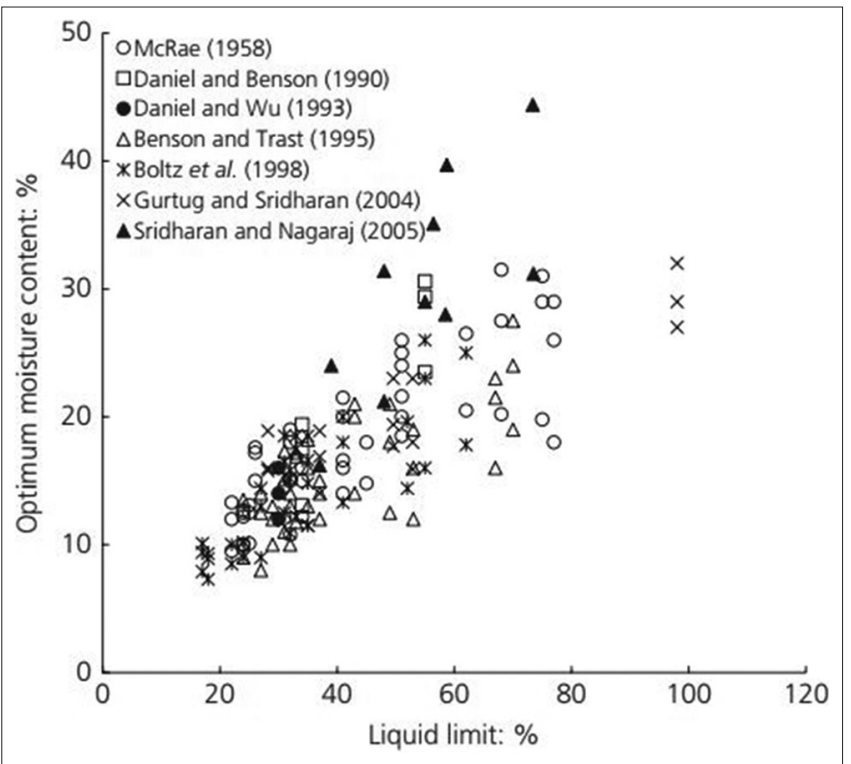

Figure 1: The relationship between optimum moisture content and liquid limit for studies from literature

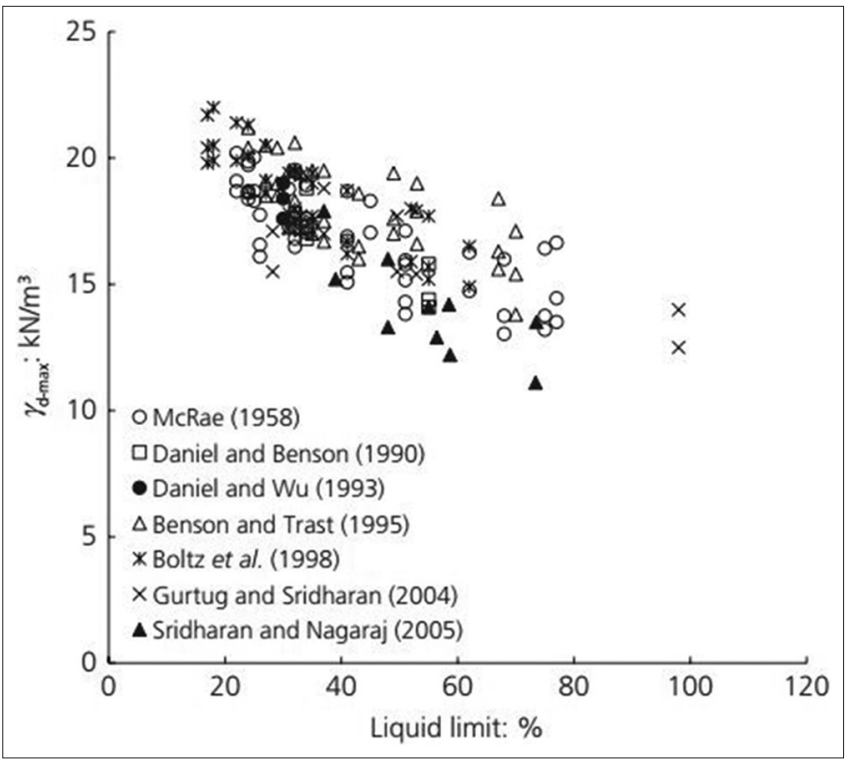

Figure 2: The relationship between maximum dry unit weight and liquid limit for studies from literature

Smaller scatter of data can be observed compared to in Figure 1.

However, Sridharan and Nagaraj (2005) expanded the studied by Pandian et al. (1997), from which a method to predict the compaction characteristics in terms of the liquid limit was suggested. They concluded that the compaction characteristics of the soil do not correlate well with both wL and plasticity index; meanwhile, wP shows a good correlation with both OMC and $\gamma_{d \text { max }}$. Based on the data from the other literature and their study, Sridharan and Nagaraj (2005) derived the following expressions:

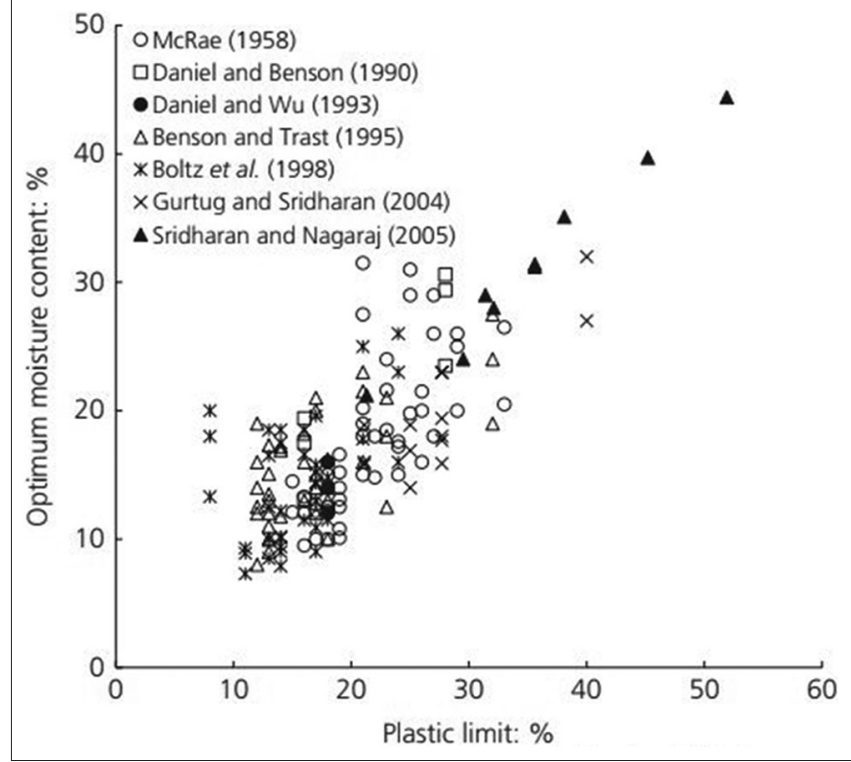

Figure 3: The relationship between optimum moisture content and plastic limit for studies from literature

$$
\begin{gathered}
\mathrm{OMC}=0.92 \mathrm{~W}_{\mathrm{p}} \\
\gamma_{\mathrm{d} \max }=0.23\left(93.3-\mathrm{W}_{\mathrm{p}}\right)
\end{gathered}
$$

They also expressed the best-fitted curve for the relationship between $\mathrm{wL}-\mathrm{OMC}$ and $\mathrm{wL}-\gamma_{d \max }$ as follows:

$$
\begin{aligned}
& \text { OMC }=0.37\left(W_{L}+12.46\right) \\
& \gamma_{d \text { max }}=0.09\left(218-W_{L}\right)
\end{aligned}
$$

Figures 4 and 5 show the plot between $\mathrm{W}_{\mathrm{p}}$ and $\mathrm{OMC}$ and $\gamma_{d \text { max }}$, respectively. In spite of the fact that scatter can also be observed, $\mathrm{W}_{\mathrm{p}}$ is likely to show a good correlation with the compaction characteristics in the study.

Nerea (2012) also quoted that the compaction characteristics can correlate well with plastic limit in comparison with liquid limit and plasticity index for a specific type of soil. He stated that plastic limit alone can be used to determine the compaction characteristics. Further, Tsegaye et al. (2017) claimed that there is a relatively good correlation between OMC and wP, and similarly, a good correlation is observed between $\gamma_{d \max }$ and wL, and wP and plasticity index together.

However, Horpibulsuk et al. (2008) and Pillai and Vinod (2015) concluded that the prediction of compaction characteristics of fine-grained soil cannot be accurate by including only one index properties (wL or wP). Prasanna et al. (2017) included both wL and wP to derive a good correlation so that an appropriate correlation can be obtained.

Therefore, in this paper, samples from different locations have been tested to investigate whether such soil index 


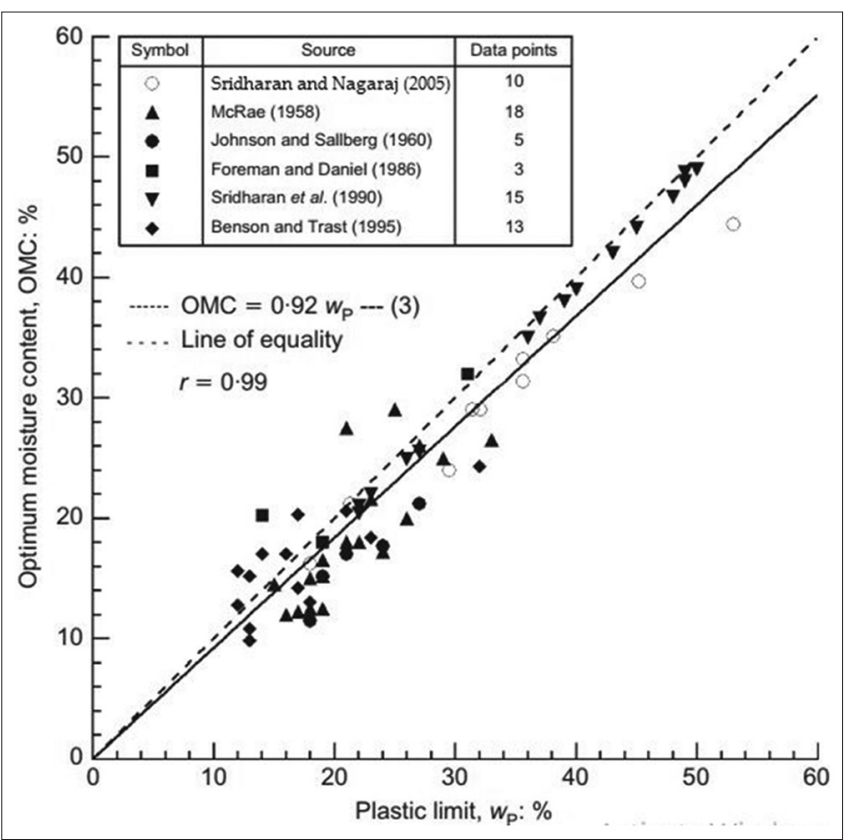

Figure 4: The relationship between optimum moisture content and plastic limit for studies from literature

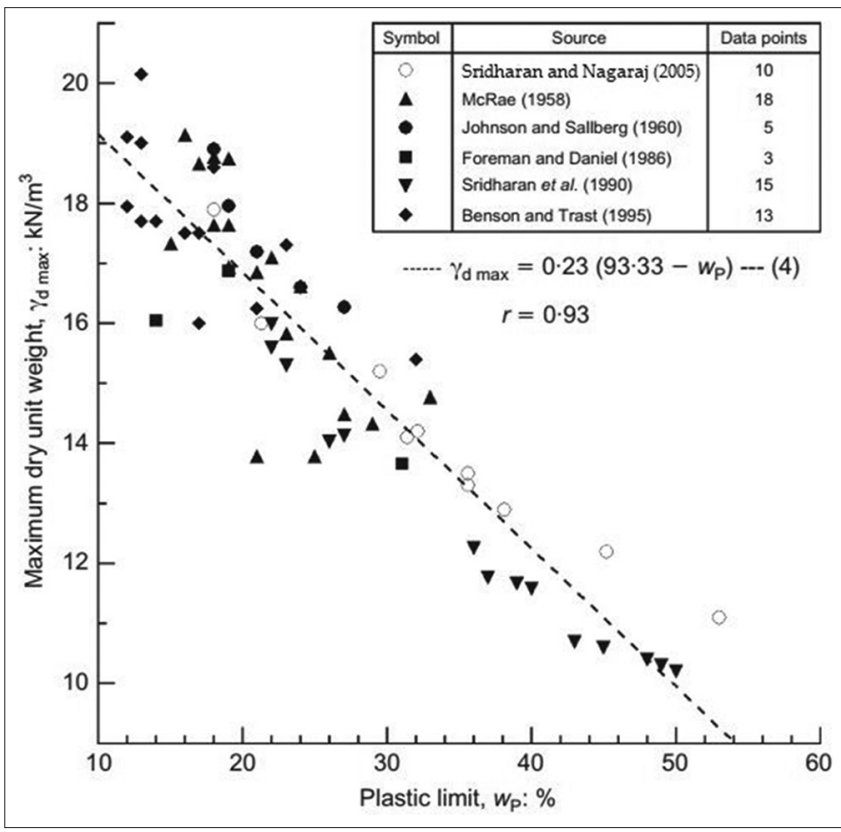

Figure 5: The relationship between maximum dry unit weight and plastic limit for studies from literature

properties as plastic limit and liquid limit can show good correlations between the compaction characteristics of the fine-grained soils, of which the index properties can provide a better correlation in comparison with another.

\section{METHODOLOGY}

To meet the aims of this work, 27 different samples were taken from different locations around Koya city. The collected samples were then brought to the Geotechnical Laboratory of College of Engineering at Koya University. About $50 \mathrm{~kg}$ disturbed samples were collected from each pit at a depth ranging from $0.50 \mathrm{~m}$ to $1.00 \mathrm{~m}$ and transported to the laboratory.

Later on, sieve analyses were carried out to determine the grain size of the collected samples. To obtain accurate grain size for the samples, wet sieving analysis (ASTM D2217) was conducted.

The liquid limit, plastic limit, and plasticity index for each soil sample were determined according to ASTM D4318 (Standard Test Method for liquid limit, plastic limit, and plasticity index of soils). For liquid limit test, Casagrande apparatus method was used and three different trials were taken for each sample. For plastic limit test, convention plastic limit test was used and three different trials were also taken for each sample.

Finally, each sample was sieved over a $4.75 \mathrm{~mm}$ sieve for testing and compacted in a $101.6 \mathrm{~mm}$ diameter mold using Standard Proctor Test procedure (ASTM D698-07). For each sample, three different trials were taken and immediately tested for water content according to ASTM D-2166. The obtained water content was used to produce a compaction curve, and the maximum dry density and $\mathrm{OMC}$ were computed for each sample using spreadsheet.

According to the sieve analysis and plasticity results, the samples were classified and majority was fine-grained soil as it is indicated in Table 1 even though the samples were taken from different locations around Koya city.

\section{RESULTS AND DISCUSSION}

In the above section, the data from other researches were collected and the relationships between the compaction characteristics and soil plasticity were also demonstrated. In this section, the new obtained data have been used to compare with the data shown in the literature. In this regard, it can be shown that to what extent the acquired data will match with the literature data, of which the index properties may indicate a good relationship with the compaction characteristics.

Figure 6 depicts a plot between OMC and plastic limit $(w P)$. The data from the literature and current data together can provide a significant scatter, from which an appropriate relationship might not be obtained. For instance, for a wP of $30 \%$, many different values of OMC can be predicted. Conversely, several different values of wP may be available for an OMC of around $20 \%$. In this 
Table 1: Index properties, compaction characteristics, and grain size distribution of the samples

\begin{tabular}{|c|c|c|c|c|c|c|c|c|c|}
\hline Sample & wP\% & $w L \%$ & $\mathrm{PI} \%$ & Max. dry density $\left(\mathrm{kg} / \mathrm{cm}^{3}\right)$ & OMC \% & F $10 \%$ & F $40 \%$ & F $200 \%$ & Soil classification \\
\hline 1 & 24 & 29.1 & 5.1 & 1860 & 16 & 52.17 & 15.1 & 6 & Well graded sand \\
\hline 2 & 32.78 & 41.2 & 8.42 & 1730 & 22 & 53.5 & 12.5 & 4.1 & Silty or clayey sand \\
\hline 3 & 18.16 & 27.72 & 9.56 & 1772 & 13.5 & 39.7 & 14.5 & 3.39 & Silty or clayey sand \\
\hline 4 & 26.423 & 31 & 4.577 & 1800 & 18 & 53.4 & 18.35 & 1.36 & Well graded sand \\
\hline 5 & 15 & 25.5 & 10.5 & 1850 & 15.5 & 53.88 & 20.79 & 0.16 & Well graded sand \\
\hline 6 & 25.266 & 35.75 & 10.484 & 1750 & 17 & 51.66 & 17.95 & 7.1 & Silty or clayey sand \\
\hline 7 & 30.297 & 38.41 & 8.113 & 1738 & 22.5 & 33.58 & 9.42 & 0.69 & Silty or clayey sand \\
\hline 8 & 24.795 & 30 & 5.205 & 1840 & 17 & 54 & 20.9 & 4 & Silty or clayey sand \\
\hline 9 & 27.448 & 37.59 & 10.142 & 1723 & 21 & 86.8 & 82.4 & 74.9 & Silty soil \\
\hline 10 & 24.26 & 34.91 & 10.65 & 1920 & 15 & 96.99 & 96.95 & 96.3 & Clayey soil \\
\hline 11 & 36.45 & 48.81 & 12.36 & 1716.9 & 19 & 99.73 & 99.62 & 97.3 & Clayey soil \\
\hline 12 & 20.17 & 33 & 12.83 & 1833 & 19 & 93.35 & 90.86 & 88.5 & Clayey soil \\
\hline 13 & 31.433 & 36.1 & 4.667 & 1861 & 17.3 & 99.89 & 93.1 & 81.3 & Silty soil \\
\hline 14 & 27.58 & 35.52 & 7.94 & 1861.2 & 11 & 99 & 98.92 & 93.1 & Silty soil \\
\hline 15 & 24.8 & 27.9 & 3.1 & 1822 & 15.5 & 94.9 & 90.92 & 86.7 & Silty soil \\
\hline 16 & 32.6 & 45.4 & 12.8 & 1776 & 16.5 & 92.64 & 77.98 & 32.9 & Silty or clayey sand \\
\hline 17 & 26.65 & 37.3 & 10.65 & 1762.5 & 17.5 & 98.9 & 96.8 & 90.4 & Silty soil \\
\hline 18 & 29.27 & 41.6 & 12.33 & 1731 & 22.5 & 98.56 & 97.94 & 95.8 & Clayey soil \\
\hline 19 & 29.2 & 32 & 2.8 & 1950 & 10 & 96.45 & 94.83 & 58.6 & Silty soil \\
\hline 20 & 20.7 & 25.3 & 4.6 & 2161 & 13 & 79.58 & 75.51 & 65.4 & Silty soil \\
\hline 21 & 29.6 & 40 & 10.4 & 1723 & 18.5 & 98.64 & 97.43 & 93.6 & Silty soil \\
\hline 22 & 20.82 & 26.3 & 5.48 & 1669.2 & 11 & 97.92 & 96.93 & 77.3 & Silty soil \\
\hline 23 & 22.21 & 26.5 & 4.29 & 2040 & 15 & 99.74 & 99.57 & 97.5 & Silty soil \\
\hline 24 & 22.3 & 28.2 & 5.9 & 2056 & 11 & 73.14 & 70.34 & 67.6 & Silty soil \\
\hline 25 & 12.84 & 42 & 29.16 & 1645 & 25 & 93.33 & 91.59 & 88 & Clayey soil \\
\hline 26 & 22.61 & 33.15 & 10.54 & 1789 & 16.5 & 84.7 & 81.54 & 69 & Silty soil \\
\hline 27 & 26.22 & 40.1 & 13.88 & 1778 & 20 & 96.92 & 95.4 & 93.2 & Clayey soil \\
\hline
\end{tabular}

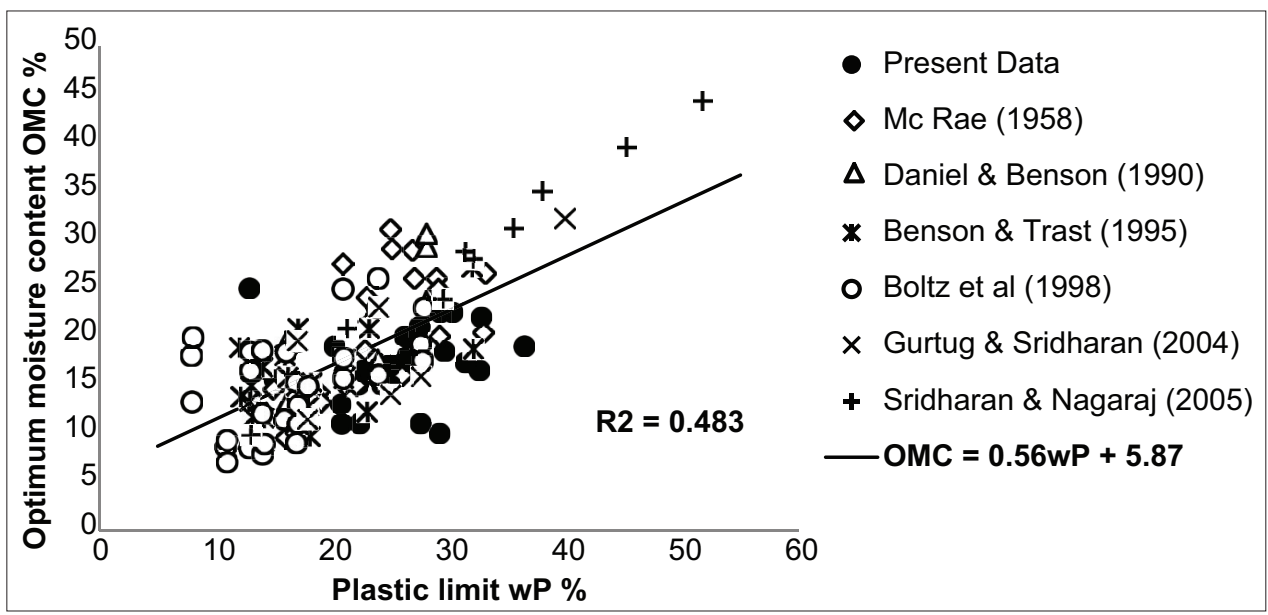

Figure 6: Present data and data from the literature for optimum moisture content and plastic limit

point of view, it can be observed that between OMC and wP a good correlation may not be suggested. Further, the best-fitted relationship for these data can be expressed as follows:

$$
\mathrm{OMC}=0.56 \mathrm{wP}+5.87
$$

However, both literature and present data have significantly deviated from the fitted curve, especially in high plasticity value.
Figure 7 illustrates a plot of OMC against wL, from which some scatter can generally be observed. However, the new obtained data matched relatively good with the data from the literature compared with the relationship of OMC with wP. From the combination with both data, it can be seen that the trend of the data maintained as OMC increases with the increment of wL. It should also be noted that for wL less than 60\%, a good relationship between OMC and $\mathrm{wL}$ is relatively available but it would not be satisfactory to 
predict OMC from wL. As it is depicted in the figure, the new relationship can be obtained as follows:

$$
\mathrm{OMC}=0.31 \mathrm{wL}+5
$$

Figure 8 demonstrates a plot of $\gamma_{d \max }$ and wL. Similar to Figure $7, \gamma_{d \max }$ can relatively correlate with the wL for those soil having smaller wL than $60 \%$. It might not also be sufficient to obtain the prediction of maximum dry unit weight as considerable scatter is available. Nevertheless, with reference to both the present and literature data, new relationship can be predicted and it is expressed as follows:

$$
\gamma_{\text {dmax }}=21.5-0.1 \mathrm{wL}
$$

The correlations proposed by Sridharan and Nagaraj (2005), illustrating that $\mathrm{wP}$ is far better than wL in predicting the compaction characteristics, have been plotted with the new data. Referring to Figure 9, it can obviously be noted that the proposed relationship between $\mathrm{OMC}$ and wP does not match well with the new data and it relatively overestimates OMC values. Similarly, the suggested correlation between $\gamma_{\text {max }}$ and wP provides some degree discrepancy and the vast majority of new data cannot be located on the proposed line by Sridharan and Nagaraj (2005), as demonstrated in Figure 10. Conversely, this correlation underestimates $\gamma_{d \max }$ values. As a result, these correlations cannot be justified for predicting the compaction characteristics.

Furthermore, the correlations established between the compaction characteristics and wL by Sridharan and Nagaraj have also been examined in Figure 11 and 12 to validate these correlations. Figure 11 shows a plot of

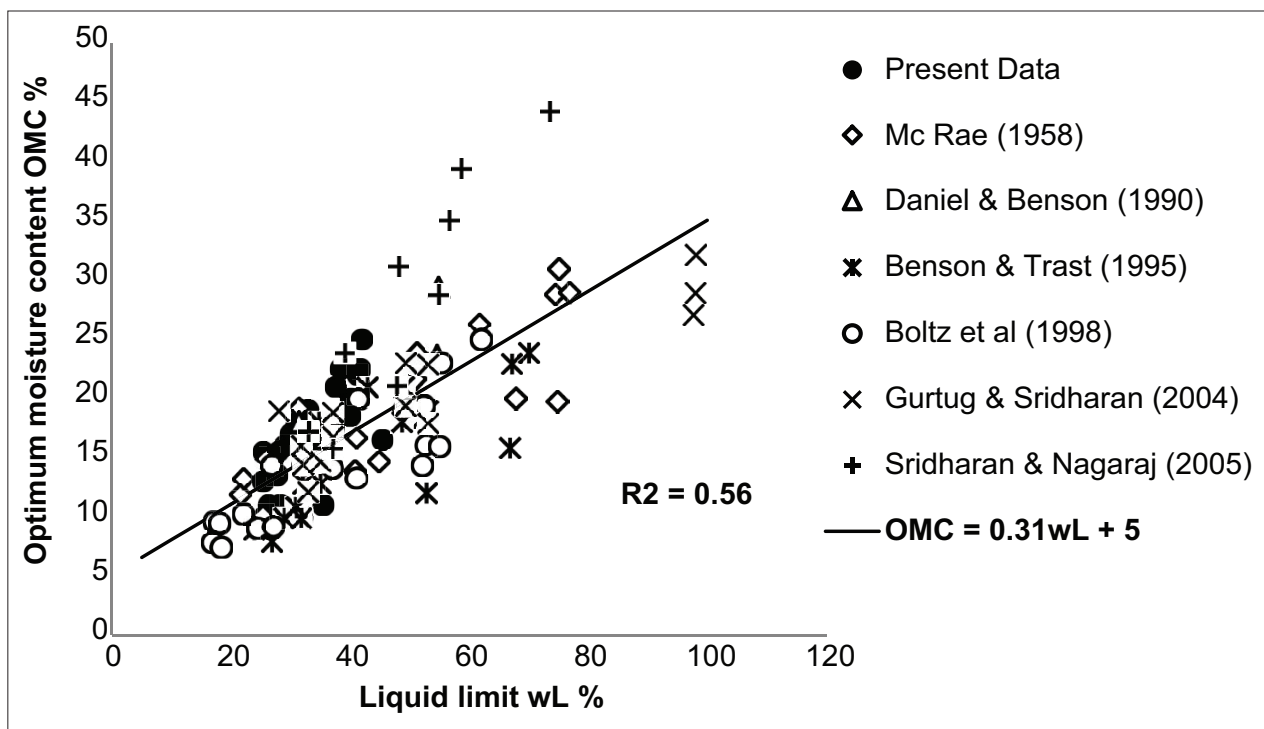

Figure 7: Present data and data from the literature for optimum moisture content and liquid limit

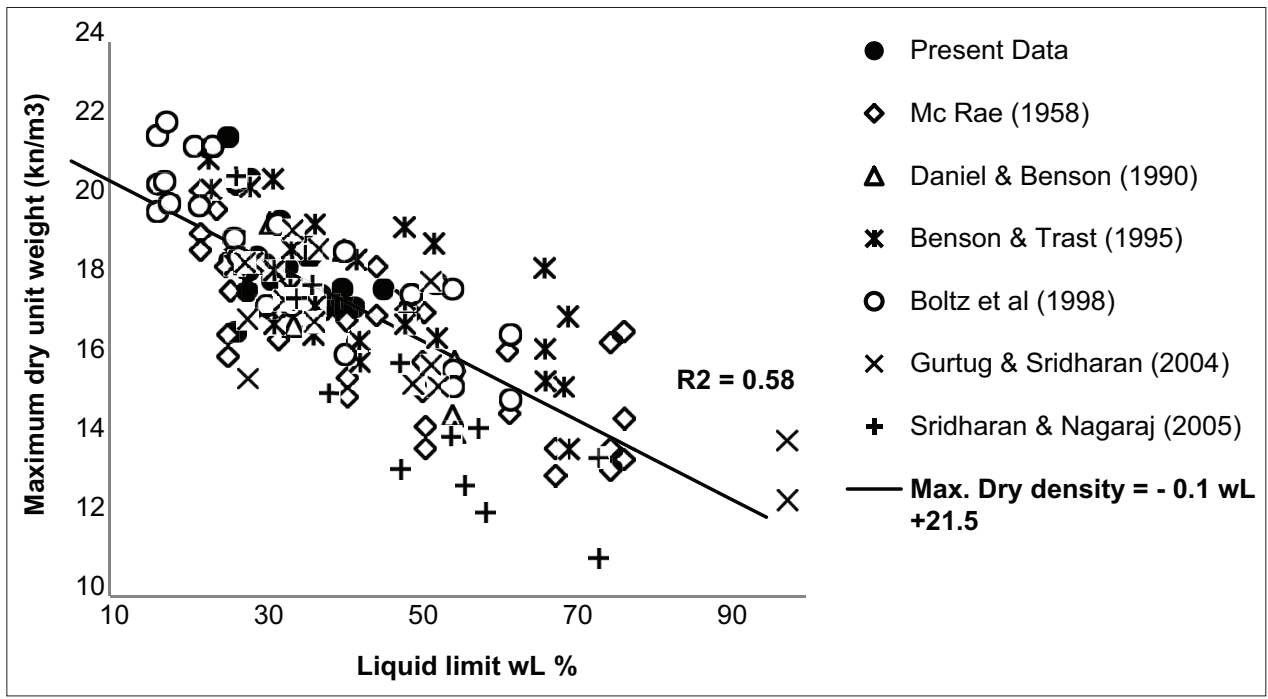

Figure 8: Present data and data from the literature for maximum dry unit weight and liquid limit 


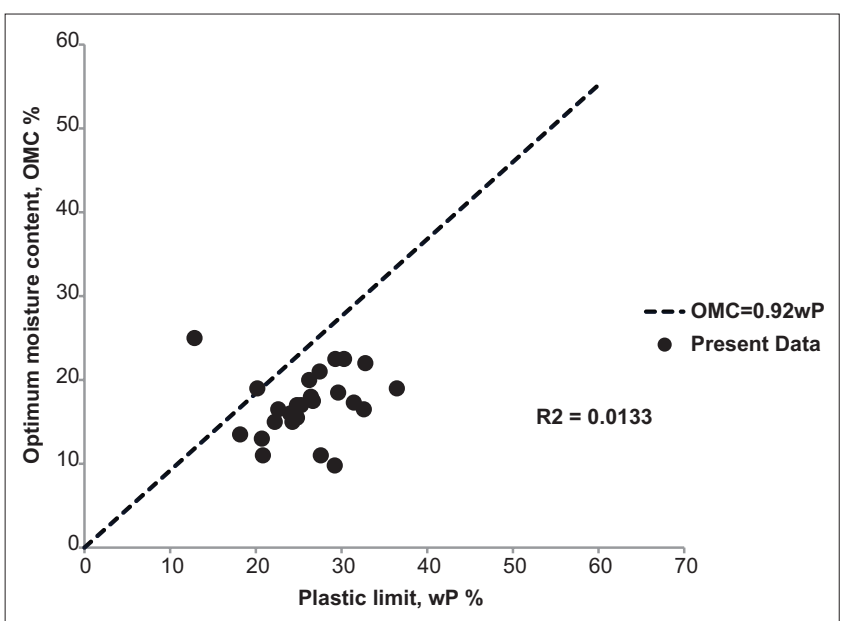

Figure 9: Present data and the proposed correlation for optimum moisture and plastic limit

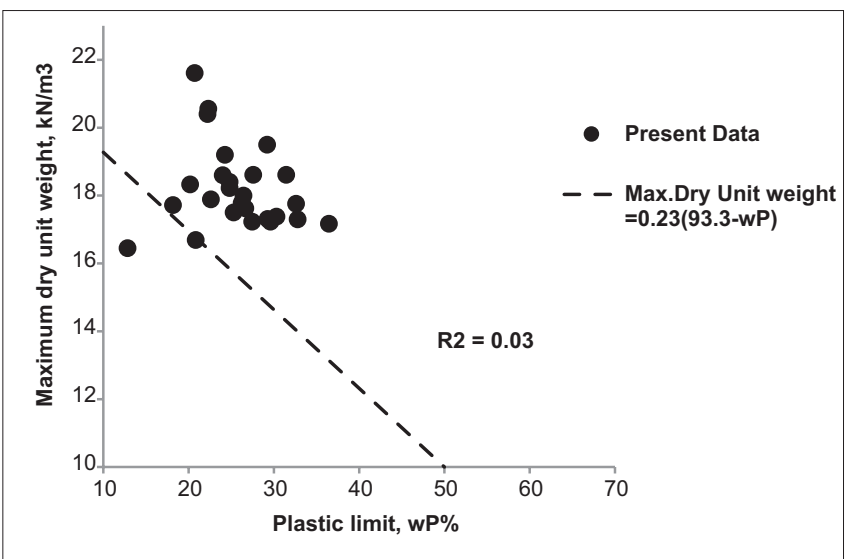

Figure 10: Present data and the proposed correlation for maximum dry unit weight and plastic limit

OMC against wL. It seems that the wL has relatively a good relationship with OMC compared to wP but not at the satisfactory level.

However, there is a poor relationship between $\gamma_{d \max }$ and wL. Similar to $\gamma_{d \max }$ and wP correlation, significant scatter can be observed between $\gamma_{d \text { max }}$ and wL correlation and the present data. The suggested correlation also underestimates the $\gamma_{d \max }$ from the present data, as shown in Figure 12.

\section{CONCLUSION}

Based on the data from the literature and present data, it can be concluded that soil index properties cannot be used to provide an accurate estimate to the compaction characteristics. Although it is thought that plastic limit is close to OMC, liquid limit is likely to correlate well but not at the satisfactory level.

The previously established correlations between soil index properties and compaction characteristics assert that

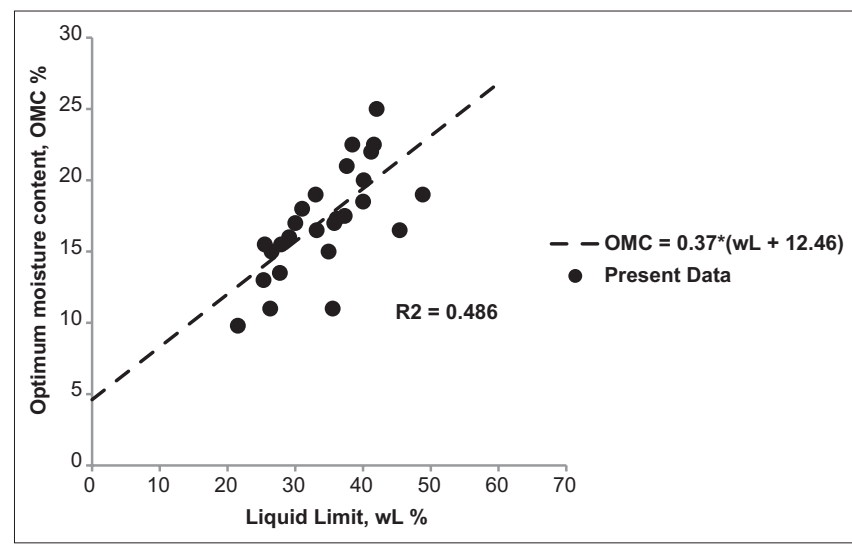

Figure 11: Present data and the proposed correlation for optimum moisture content and liquid limit

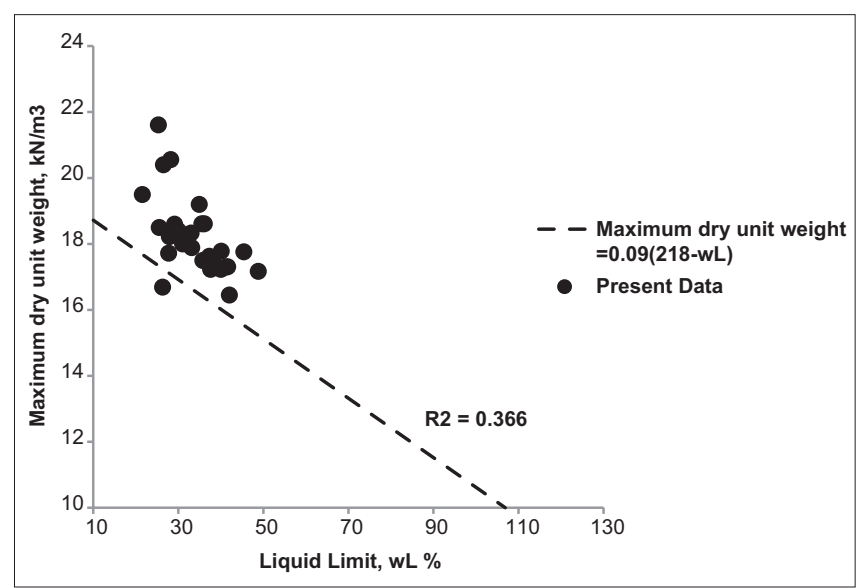

Figure 12: Present data and the proposed correlation for maximum dry unit weight and liquid limit

plastic limit provides better relationship than liquid limit and plastic limit is justified to estimate both OMC and $\gamma_{d \text { max }}$. However, this research disagrees with these findings. The proposed OMC and wL and $\gamma_{d \max }$ and wL correlation matches better with new obtained data but with some notable scatter.

Furthermore, even though new correlations between compaction characteristics and soil index properties are obtained by combining both the literature and present study data, they are still not sufficient to provide compaction characteristics from soil index properties.

\section{ACKNOWLEDGMENT}

The authors declare that no fund was received for this research.

\section{REFERENCES}

Benson, C. H. and J. M. Trast. 1995. Hydraulic conductivity of thirteen compacted clays. Clays Clay Miner. 43: 669-681. 
Blotz, R. L., C. H. Benson and G. Boutwell. 1998. Estimating optimum water content and maxi dry unit weight for compacted clays. J. Geotech. Geo-Environ. Eng. 124(9): 907-912.

Budhu, M. 2015. Soil Mechanics Fundamentals. $1^{\text {st }}$ ed. John Wiley and Sons, United Kingdom.

Daniel, D. E. and C. H. Benson. 1990. Water content density criteria for compacted soil liners. J. Geotech. Eng. 116(12): 1181-1190.

Daniel, D. E. and Y. K. Wu. 1993. Compacted clay liners and covers for arid sites. J. Geotech. Eng. 119(2): 223-237.

Gurtug, Y. and A. Sridharan. 2004. Compaction behaviour and prediction of its characteristics of fine-grained soils with particular reference to compaction energy. Jpn. Geotech. Soc. Soils Found. 44(5): 27-36.

Horpibulsuk, S., W. Katkan and A. Apichatvullop. 2008. An approach for assessment of compaction curves of fine grained soils at various energies using one point test. Soils Found. 48(1): 115-126.

McRae, J. L. 1958. Index of Compaction Characteristics. Symposium on Application of Soil Testing in Highway Design and Construction, ASTM Special Technical Publication No. 239. p119-127.

Nerea, A. 2012. Prediction of Compaction Characteristics from
Atterberg Limits for Fine-grained Soils. MSc. Thesis, Department of Civil Engineering, Addis Ababa University, Ethiopia.

Pandian, N. S., T. S. Nagaraj and M. Manoj. 1997. Re-examination of compaction characteristics of fine-grained soils. Géotechnique. 47: 363-366.

Pillai, G. A. and P. P. Vinod. 2015. Re-examination of compaction parameters of fine-grained Soil. Ground Improv. 169(3): 1-2.

Powrie, W. 2004. Origin and Classification of soils Soil Mechanics: Concepts and Applications. Spon Press, Oxon. p47-48.

Prasanna, H. S., D. Harshitha, D. K. Singh, K. H. Krishnegowda and S. Suhruth. 2017. Correlation of compaction characteristics of fine-grained soils using atterberg limit. Int. J. Eng. Res. Technol. 6(6): 23-30.

Sridharan, A. and H. A. Nagaraj. 2005. Plastic limit and compaction characteristics of fine-grained soils. Ground Improv. 9(1): 17-22.

Sridharan, A., S. M. Rao and S. Joshi. 1990. Classification of expansive soils by sediment volume method. Geotech. Test. J. 13(4): 375-380.

Tsegaye, T., F. Henok and A. Tadesse. 2017. Correlation between compaction characteristics and atterberg limits for fine grained soils found in Adiss Ababa. Int. J. Sci. Eng. Res. 8(6): 357. 